\title{
Alimentar a la humanidad: desafíos actuales de la agricultura en el mundo
}

\section{Bernard Guiffault*}

La agricultura se ha vuelto una prioridad. Entre 2007 y 2008 los precios de los alimentos han sufrido alzas inéditas, sus valores se han duplicado y hasta triplicado, provocando movilizaciones urbanas: 'revueltas del hambre', sobre todo en una veintena de países en África, una decena en Asia, y tanto en países emergentes (Indonesia o México) como en países muy pobres (Haití o Nigeria).

La alarma en el resto del mundo fue brutal. Se creía que el problema de las penurias alimentarias se estaba regulando y que las hambrunas no eran más que casos locales excepcionales. En los países del Norte se vivía la ilusión de la abundancia agrícola: no se pensaba más que en reducir los excedentes y hacer menos productiva la agricultura. Pero en pocas semanas surgió el antiguo miedo malthusiano de carencia alimentaria y, por primera vez, el fenómeno se volvió mundial. A ello se añadió la crisis energética y la crisis financiera con el trasfondo de una crisis ecológica latente.

En 2008, el Banco Mundial preconizó invertir más en la agricultura de los países en desarrollo. Tres elementos justificaban esta reinversión: primero, los objetivos fijados en términos de desarrollo "consistentes en reducir a la mitad hasta el 2015 la proporción de población que vive en la extrema pobreza y sufre hambre crónica". Los más pobres son de hecho mayoritariamente rurales y agricultores. Segundo, cumplir el reto alimentario en el horizonte de 2050, cuando el planeta cuente con unos 9 mil millones de habitantes. Tercero, la adaptación al cambio climático, que se traducirá en un aumento de las temperaturas, una modificación del régimen de las precipitaciones, un mayor número de fenómenos extremos (sequías, inundaciones, tempestades), con una significativa disminución del rendimiento de ciertas regiones ya frágiles.

La cuestión alimentaria es compleja y tiene numerosas dimensiones: un enfoque nutricional en términos de calorías; económico, en términos de relación entre oferta y demanda; social, en términos de participación en el valor añadido; agronómico, en términos de sustentabilidad de los sistemas agrarios; ecológicos, en términos ambientales; jurídicos, en términos de derechos de propiedad de los

Geógrafo. Profesor agregado. Conferencia tenida en la Universidad Jean Monet de Saint-Etienne, enero de 2011. bernard.guiffault@wanadoo.fr 
campesinos; políticos, en términos de control de las redes estratégicas de las canales alimentarios. El procedimiento geográfico permite cruzar todos estos enfoques.

En este artículo presentaremos las crisis alimentarias recientes y después trataremos las evoluciones en el largo plazo de la demanda y de la oferta, para finalmente abordar las posibles evoluciones.

\section{Las crisis de 2008 y 2010}

La subida disparada de los precios en 2008 se explica por factores coyunturales: las cosechas en los grandes países exportadores (sucesión de dos sequías en Australia, donde la producción quedó reducida a la mitad respecto del promedio habitual, e intemperies en Europa central en 2007). En realidad basta una reducción coyuntural de la producción del 10\%, ligada a malas cosechas en los grandes países productores del hemisferio Norte y en Australia, para que los precios aumenten de manera desproporcionada. De hecho, existe en el ámbito agrícola La ley de King, según la cual toda variación de la producción, por mínima que sea, se traduce en fluctuaciones de precios que se multiplican. En el plazo de pocos meses, el precio de la tonelada de trigo, maíz, arroz, tres productos que por sí solos representan las $2 / 3$ partes de la alimentación mundial, pasa de niveles históricamente deprimidos a picos: el precio del trigo se triplica llegando a 300 dólares la tonelada en 2007, 450 en 2008 contra los 100 dólares de los años anteriores.

Razones especulativas y compras de provisión: el miedo a la carencia, la voluntad de reservar su producción para el mercado interno incitan a los grandes países exportadores como Tailandia, India y Vietnam a restringir e incluso suspender sus exportaciones. De otro lado, en un contexto mundial donde muchos capitales están disponibles para las inversiones a corto plazo, una especulación masiva en los mercados a plazo de Chicago, Kansas City, New York, Minneapolis y Londres provoca que se embalen los precios. En los mercados a corto plazo las promesas de compra y venta se escalonan en el tiempo. Los agentes se cubren contra las fluctuaciones de los precios del mercado - por eso estos mercados desempeñan un papel de seguridad-, pero la especulación tiende a exagerar estas fluctuaciones. 
La escalada de los precios del petróleo, que supera los 150 dólares el barril en junio 2008, acentúa el alza. Esto encarece los costos de los transportes internacionales y también el precio de lo que se llama insumos necesarios para la producción agrícola, proporcionados por la industria química a partir de derivados del petróleo: carburantes de los tubos de riego y tractores, productos fitosanitarios (pesticidas): insecticidas, herbicidas, fungicidas y fertilizantes.

En el mediano plazo las evoluciones en curso eran inquietantes. La FAO había advertido desde 2005 la reducción de los depósitos internacionales de cereales. Poco tiempo antes el mundo parecía desplomarse bajo el peso de un 'excedente cerealero', que difícilmente lograba canalizarse hacia los mercados internacionales. A inicios de 1980 las reservas habían quedado reducidas de manera sensible bajo las presiones de los pesos pesados de la agricultura mundial: la Unión Europea y Estados Unidos, al mismo tiempo que importantes superficies de tierra agrícola estaban heladas.

La subida de los carburantes acentuó la penuria. En nombre del desarrollo sustentable un gran número de países reorientaron una parte de su producción agrícola de cereales y oleaginosas hacia la demanda energética, a fin de economizar recursos no renovables. El anuncio de estos planes de producción de agrocarburantes desembocó en una concurrencia potencial entre producción alimentaria y energética y empujó los mercados a la subida, en particular la del maíz.

Las políticas de liberalización de los intercambios y los bajos precios agrícolas mundiales en los años precedentes han aumentado la dependencia respecto de las importaciones de productos alimentarios y ha expuesto numerosos países a la volatilidad de los precios internacionales. El periodo de tensión de la primavera 2008 no duró: desde el verano las buenas cosechas hicieron recaer los precios. El precio del petróleo se hundió. En octubre 2008 ya no se hablaba de crisis alimentaria sino de crisis financiera. Pero la volatilidad de los precios no desaparecía.

A finales de 2010 se dispararon los precios de los productos alimentarios, rebasando la cumbre de 2008, según las cifras publicadas por la FAO a inicios de enero de 2011. Sobre la base de los precios de 2002-2004, el índice de los precios de los alimentos era de 191 en 2008, de 174 en enero de 2010 y 215 en diciembre de 2010. El índice de los cereales, 238 en 2008, había caído a 170 en enero de 2010, pero alcanzaba 238 en diciembre de 2010, recuperando los picos 
de 2008. Para el trigo, los precios casi han doblado en el año 2010: 130 euros la tonelada en julio y 250 en enero de 2011. El trigo es un cereal que, a diferencia del maíz, es esencialmente de consumo directo bajo formas diversas: pan, pastas alimentarias, galletas, sémola... Las 4/5 partes de la ayuda alimentaria mundial son distribuidas en forma de trigo. En 2009-2010 los intercambios de trigo han supuesto 127 millones de toneladas, un $18 \%$ de la producción mundial de 680 millones de toneladas.

Egipto es, por ejemplo, el primer importador mundial, con 83 millones de habitantes y un crecimiento anual de 1,9\%; es decir, 1,5 millones más de egipcios al año. El consumo diario de pan por habitante es tres veces superior al de un país como Francia. El pan se vende barato gracias a enormes subvenciones estatales. Se mide la gravedad de su dependencia alimentaria al ser comparable con la de Argelia, Túnez o Irak.

¿Cuáles son las causas del alza de los precios de los cereales del verano de 2010? Se encuentran las mismas que en 2007-2008. En Rusia la sequía del verano de 2010 ha destruido un cuarto de la superficie cerealera del país, segundo exportador mundial de trigo. En realidad, fue afectada por la sequía toda la cintura cerealera del Mar Negro: $5.000 \mathrm{~km}$ de tierras negras, las más fértiles del mundo, desde Ukrania hasta Kazakistán pasando por Rusia. En 2008-2009 la región había logrado exportar 35 millones de toneladas de trigo (18 de Rusia, más 11 de Ukrania y 6 de Kazakistán) contra 27 millones de toneladas de los Estados Unidos. Es la resurrección de uno de los más antiguos graneros del mundo, que había ya en la Antigüedad alimentado Atenas y después Roma, y que rencuentra su lugar de primer exportador de trigo mundial, que había ocupado antes de 1917 en el contexto del imperio ruso. La colectivización de los años treinta acompañada de una auténtica guerra contra los campesinos (deportaciones masivas y hambre organizada) y la instalación de los kolhozes habían arruinado la región, haciendo de la URSS el primer importador mundial de cereales en los años setenta y ochenta.

Habría un potencial de exportación de 100 millones de toneladas a condición de invertir en las infraestructuras de almacenamiento y exportación. Esta se sitúa además en la proximidad de la principal región deficitaria de trigo del planeta: África del Norte y Medio Oriente. Las consecuencias de la mala cosecha han sido: el embargo de las exportaciones de trigo por parte de Rusia, y de 
las exportaciones totales de la región de 10 millones de toneladas en 2010 contra 35 millones en 2009. Canadá, tercer exportador mundial, víctima de fuertes lluvias, ha almacenado una cosecha más débil que de costumbre. Europa retrocedió también; solo los Estados Unidos tuvieron muy buen año. Las cosechas en el hemisferio Sur no han compensado este déficit.

Las inundaciones en el norte de Australia y las fuertes lluvias en los Estados del sudeste, grandes productores de trigo, hacen temer una cosecha mediocre. La cosecha de Argentina está amenazada por la sequía. Las consecuencias son un alza de los precios que provoca manifestaciones de cólera popular como en 2008. Revueltas del hambre estallan en Mozambique a principios de septiembre de 2010 a consecuencia del anuncio del alza de $25 \%$ del precio del pan. Mensajes a sus teléfonos móviles han sido enviados a millares de mozambiqueños para protestar contra la carestía de la vida. Un SMS ha trastornado el país: "Mozambique prepárate para el gran día de huelga". En pocas horas miles de personas se juntaron en Maputo para protestar contra el alza de los precios. Desbordados por la afluencia récord de las manifestaciones, los policías han utilizado armas de fuego real para disolver el movimiento y devolver la calma al país. Los levantamientos han costado al menos 123 víctimas, muchos cientos de heridos, más de 400 personas detenidas. Tres meses más tarde, a principios de enero 2011, las alzas de los precios alimentarios son igualmente la causa de las manifestaciones en Argelia, Túnez y Egipto.

\section{La evolución de la demanda}

\section{Los aspectos cuantitativos de la demanda}

Las evaluaciones en cifras deben ser tomadas con precaución dada la dificultad de tener medidas exactas fiables en los países del Sur. La producción agrícola del planeta se sitúa de manera global y teórica a un nivel suficiente para cubrir las necesidades alimentarias del conjunto de la humanidad: la disponibilidad teórica media en relación a la oferta energética por habitante es de 2800 kilocalorías por día, superior a los 2150-2400 kilocalorías que los nutricionistas consideran como necesarias y suficientes para atender las necesidades de un individuo medio situado en condiciones medias. Sin embargo, se considera que 
las disponibilidades energéticas deben representar 1,3 veces las necesidades para estar en condiciones de eliminar la subalimentación, y ello para tener en cuenta las desigualdades de acceso a la alimentación y las pérdidas que son descuidadas en el cálculo de las disponibilidades. En estas condiciones, 2.800 calorías por persona y por día apenas bastan.

A escala continental las cosas cambian. En los países del Norte, el consumo energético medio es en conjunto superior a 3.200 kilocalorías por persona: 3.750 en Estados Unidos, 3.600 en Francia, 3.500 en Alemania, con la excepción notable de Japón: 2.750 kilocaloría por día'. Hay, sin embargo, 19 millones de personas sub-alimentadas en los países del Norte.

En los países del Sur la media global parece casi satisfactoria con un consumo energético cotidiano medio de 2.700 kilocalorías, pero las situaciones son muy contrastantes: 3200 kilocalorías en los Emiratos Árabes, 3.000 en Kuwait, en Corea del Sur y Brasil, 2.900 en China, inferior a 2.500 en India, y menos de 2.200 en Bangladesh así como en la mayor parte de los países de África subsahariana.

¿Cuáles son las cifras del hambre? El hambre es una carencia absoluta de alimentación para poblaciones enteras, que acarrea la muerte temprana si no se hace nada por interrumpir el proceso. En el siglo XX, las hambrunas estuvieron estrechamente ligadas a perturbaciones políticas y guerras: Sudán, Irak, Corea del Norte en 1990, Etiopía 1999-2000 y 2002-2003, Madagascar 1985-1986.

Las subalimentación es el hambre silenciosa. Es el desequilibrio de la ración alimentaria en cantidad, la subnutrición en calidad, la malnutrición. En 1970 la FAO calculaba 900 millones de subalimentados: un habitante sobre tres de los países en desarrollo; alrededor de un tercio. En 2009 con mil millones, el número de subalimentados comienza a aumentar; es la consecuencia de la crisis alimentaria de 2007-2008, de la crisis económica que ha eliminado trabajos y disminuido la ayuda a los expatriados. El alza de los precios de los cereales ha sido la causa del aumento de 150 millones de personas subalimentadas. En 2001, con 925 millones, aparece una reducción, pero la cifra se mantiene superior a las anteriores a la crisis de 2008. Si la cifra marca un progreso, permanece netamente más elevada que el primer Objetivo de Desarrollo del Milenio (ODM 1), que es reducir el porcentaje de personas subalimentadas, que era del $20 \%$ de la población de los países subdesarrollados (PVD) en 1990 a 10\% en 
2015; o sea, una disminución de 420 millones en 2015. El ODM de dividir por dos el número de personas malnutridas hasta 2015 resulta inalcanzable.

El examen del mapa del hambre en el mundo, en valores relativos, muestra que Asia es el continente que más ha progresado: China y todo el Asia oriental. Es en Asia del sur donde el hambre continúa: India, Pakistán, Bangladesh, en razón de la extrema pobreza. El continente del hambre sigue siendo África con porcentajes de $30 \%$ y más; en países que sin embargo podrían nutrirse, África central y austral en particular: 75\% en República Democrática del Congo, 66\% en Eritrea, $66 \%$ en Burundi.

En valor absoluto, los dos países que tienen el mayor número de personas subalimentadas son China (150 millones, el 12\% de la población total) e India (210 millones, $20 \%$ de la población total). India y China concentran 37\% de la población subalimentada. Globalmente se cuentan más personas subalimentadas en Asia (578 millones) que en África subsahariana (239 millones), aunque las poblaciones muestran una mejoría en conjunto de la situación alimentaria de las poblaciones asiáticas y una degradación en África y Oriente Próximo.

El caso de Brasil, convertido en uno de los más grandes exportadores de productos agrícolas del mundo con 14 millones de personas, $8 \%$ de la población subalimentada, muestra bien que son las desigualdades sociales y la extrema pobreza la razones principales de la subalimentación y no tanto las insuficiencias globales de producción agrícola. Según la ONU, 80\% de personas subalimentadas viven en el medio rural. Los más afectados son las mujeres embarazadas o que amamantan y los niños. Un hambre silenciosa, poco masmediatizada y poco conocida a pesar de su amplitud. Sin embargo, cerca de 9 millones de personas mueren cada año a consecuencia directa o indirecta del hambre, de las cuales 6 millones son niños menores de 5 años.

\section{Los aspectos cualitativos}

Las estadísticas de la FAO muestran que 3 mil millones de personas sobre un total de 6,5 mil millones están confrontadas en grados diversos con problemas de salud ligados a la malnutrición. Por carencias: para 2 mil millones se trata de carencias en micronutrientes (hierro, vitamina A, yodo y zinc). La carencia en hierro llega a provocar la anemia caracterizada por una fatiga intensa 
permanente. La carencia de yodo es origen de atraso mental; la carencia en vitamina A genera alteraciones de la vista y una baja de las defensas inmunitarias. Un tercio de la humanidad se encuentra así más vulnerable a la enfermedad y la muerte.

Por exceso: para 1,6 mil millones, se trata de excesos de grasas y azúcares que llevan a situaciones de sobrepeso, obesidad que favorece las enfermedades cardiovasculares, diabetes, hipertensión arterial. El índice de masa corporal (peso dividido por el volumen de la talla) es el criterio utilizado para definir la obesidad, cuando supera $30 \mathrm{~kg}$ y el sobrepeso cuando se sitúa entre 25 y $30 \mathrm{~kg}$. La obesidad afecta a 400 millones de personas y el sobrepeso a 1.200 millones.

Un mapa de la obesidad en el mundo muestra que el fenómeno es más frecuente en el Norte que en el Sur. En el plano social es interesante notar que en los países pobres son más bien los ricos quienes se encuentran concernidos por la obesidad, mientras que en los países ricos son más bien los pobres quienes consumen más los productos de baja gama de la industria agroalimentaria. Factores culturales intervienen igualmente en África del Norte y Oriente Próximo, la obesidad aparece con frecuencia en la mujeres en razón de su estatus social, que hace que salgan poco del domicilio familiar y que practiquen poca actividad deportiva. En Francia 11\% de personas, de más de 15 años, son obesas, $40 \%$ con sobrepeso; en Estados Unidos 30\% de los adultos son obesos y dos tercios de la población tienen sobrepeso.

Para los expertos médicos el régimen alimentario suficiente para un individuo medio de los países ricos debería contar diariamente con 2800-3000 calorías en valor energético, 80 a 100 gramos de lípidos, una pequeña mitad de origen animal, y de 80 a 100 gramos de proteínas, igualmente una pequeña mitad de origen animal. En los países ricos el consumo de proteínas por persona es con frecuencia superior a 100 gramos: 114 en Estados Unidos, 118 en Francia, 100 en Alemania. Por el contrario, en los países pobres dicho consumo puede caer a niveles muy bajos, inferiores a 50 gramos por día por persona: 48 en Bangladesh, 47 en Haití, 39 en Mozambique. En Brasil se ha pasado de 64 gramos en 1980 a 83 gramos hoy en día; en China de 54 gramos a 82 gramos en el curso del mismo periodo; en India solo de 51 a 57 gramos. Estas cifras evidencian que poblaciones cada vez más numerosas han entrado en la transición alimentaria. 


\section{La transición alimentaria o nutricional}

Cada país reproduce a su manera un modelo de evolución y de transición alimentaria (de igual manera que la transición demográfica). En referencia al caso de Francia, la primera fase se sitúa en el siglo XIX: la ración alimentaria cotidiana progresó de manera constante pasando de menos de 2.000 kilocalorías a más de 3.000 , en relación con un consumo creciente de cereales y feculantes. Se come más. En el siglo XX, la segunda fase se tradujo en una disminución del consumo indirecto de cereales y feculantes compensado por un aumento del consumo de azúcar, grasas, productos animales (carnes, leche, queso). Paralelamente, el consumo de frutas y legumbres creció. Hubo una clara diversificación de los regímenes alimentarios de los franceses, marcada por un creciente consumo de proteínas de origen animal y de vitaminas, así como de diferentes oligoelementos contenidos en frutas y legumbres. Se come mejor y todavía un poco más: un aporte diario de 3.600 kilocalorías por persona adulta. Una tercera fase se inició: regímenes alimentarios más ligeros y la búsqueda de productos de calidad proveídos por la agricultura biológica o productos AOC (apelación de origen controlada).

Se nota que el consumo directo de cereales nunca ha sido tan elevado, y se opera a través de un consumo creciente de carnes, productos lácteos y de manera general de proteínas animales. Actualmente se necesitan $2 \mathrm{~kg}$ de cereales para producir $1 \mathrm{~kg}$ de carne de pollo, $4 \mathrm{~kg}$ para producir $1 \mathrm{~kg}$ de carne de cerdo. Más de un tercio de los cereales producidos están destinados a la alimentación animal (más de la mitad en los países ricos). El enriquecimiento de fracciones cada vez más numerosas de la población en los países emergentes y en los países exportadores de petróleo conduce así a una demanda creciente de cereales, y tanto más que las carnes que son consumidas son carnes granívoras: pollo y cerdo.

\section{Los principales factores de crecimiento de la demanda}

Tres factores principales provocan un aumento de la demanda: 1. El mejoramiento del nivel de vida es el origen de la transición alimentaria; concierne esencialmente a los países emergentes, donde se estima que las clases medias 
han duplicado su población desde inicios de los años noventa. 2. La creciente urbanización asociada en parte al factor anterior: $37 \%$ de la población de los países del sur eran urbanos en 1990, mientras que hoy es del 50\% y según la FAO será del $70 \%$ en 2050 . 3. El principal factor del aumento de la demanda alimentaria es el crecimiento demográfico. El resurgimiento del malthusianismo está vinculado con la explosión demográfica de los países del Sur y a la subida del crecimiento sostenible entendido como la preservación de un medioambiente fijado en los años noventa. Surge el temor de una población que crece más rápida que las subsistencias. Malthus publica en 1789 el Ensayo sobre el principio de la población, cuando la humanidad contaba con mil millones de seres humanos. Para él "no hay lugar para todo el mundo en el banquete de la humanidad".

El rápido aumento de la población mundial en los años setenta corresponde sin embargo a un apogeo. De hecho, en 50 años la fecundidad de las mujeres ha sido dividida por más de dos y la humanidad franqueó el umbral histórico en 2003: la mayoría de los seres humanos viven desde entonces en un país donde la fecundidad es inferior a 2,1 hijos por mujer; inferior al umbral de reemplazamiento generacional. En valor absoluto, el crecimiento demográfico ha comenzado a debilitarse: en 1992 se incrementó en 100 millones de personas, hoy el crecimiento anual es más cercano a 70 millones y se reduce cada año. Los demógrafos coinciden en el hecho de que la población mundial debería alcanzar 9 mil millones en 2050, para estabilizarse después.

El crecimiento demográfico continuará en el Sur todavía durante medio siglo, en razón de lo que se llama impulso demográfico: la llegada en edad de procrear de las clases jóvenes, el boom demográfico. Se pasaría de 6,7 a 9 mil millones; es decir, un aumento de 2,3 mil millones de seres humanos entre 2010 y 2050. En África, de 906 millones a 2 mil millones; en Asia, de 3,9 a 5,2 mil millones. Globalmente, a inicios de los años dosmil, para 6 mil millones de personas, la producción es de 2 mil millones de toneladas de cereales. JP Charvet estima que se requieren 350 millones de toneladas suplementarias para mil millones de habitantes, con una alimentación no calcada sobre la de los países ricos (la actual producción de cereales de Estados Unidos es de 330 millones de toneladas). En 2050 será necesario producir un poco menos de mil millones de 
toneladas suplementarias solo para mantener los niveles actuales de consumo. Se mide la amplitud del desafío.

\section{Las evoluciones de la producción agrícola}

\section{Los dos factores de crecimiento de la producción agrícola}

\section{a. El aumento de las superficies cultivadas}

En el siglo XIX la población mundial pasó de 1 a 2 mil millones de personas entre 1819 y 1920 : este crecimiento se basó en el aumento de las superficies cultivadas, la desaparición de los barbechos y la ampliación de la superficie cultivada en decenas de millones de hectáreas en los 'nuevos países': Estados Unidos, Canadá, Argentina, Brasil, África del Sur, Australia y Nueva Zelanda. Desde los años sesenta el crecimiento de las superficies cultivadas ha desempeñado un papel marginal. Es la progresión de los rendimientos por hectárea cultivada lo que ha tomado el relevo. Mientras que la población mundial pasaba de 4,4 mil millones en 1980 a 6,4 en 2004, un aumento del 44\%, las tierras trabajadas han pasado de 1350 millones de hectáreas en 1980 a 1400 millones en 2000; un aumento del 4\% en 20 años. Habrá que añadir el total de plantaciones de 1448 a 1544 millones de hectáreas de tierras emergentes. Se trata de una débil progresión, pues de 13 a 14 millones de hectáreas son roturadas anualmente, pero las pérdidas anuales son equivalentes a causa de la erosión de los suelos y la ampliación urbana.

\section{b. La progresión de los rendimientos y de la productividad}

La producción agrícola mundial ha aumentado de manera muy importante, su crecimiento está en más del 50\% desde los años setenta, esencialmente por el progreso de los rendimientos promovido por el desarrollo técnico: nueva variedad de cultivos con un alto potencial de rendimiento, razas animales muy mejoradas, crecientes cantidades de insumos y productos fitosanitarios. Recursos destinados al riego, cuyas superficies se han multiplicado por 5 en el mundo en el curso del siglo XX. Se trata de la llamada agricultura 'productivista', orientada por las eficacias técnicas y desarrollada en el marco de la 'segunda revolución verde' de los países del Norte y de la 'revolución verde’ de los países del Sur. 
El rendimiento del trigo ha pasado en Francia de 25 quintales en los años cincuenta a más de 75 a inicios de los años dosmil, con picos de 90 a 100 quintales en el centro y norte de la cuenca parisina. Los rendimientos de leche por vaca se han doblado o triplicado. El dominio del agua ha permitido en diferentes regiones de Asia aumentar los rendimientos y pasar de una a dos cosechas de arroz por año. De 10/20 quintales por hectárea con riego y 100/120 con doble cultivo anual regado; tanto más que las nuevas variedades con alto rendimiento de la revolución verde presentan con frecuencia ciclos vegetativos más cortos.

Las diferencias de rendimientos son considerables. Agricultores que cultivan en seco cereales poco productivos como mijo y sorgo en el Sahel africano no pueden obtener más de 5 a 6 quintales por hectárea, contra 100 en las regiones más intensivas ya citadas. Las diferencias de productividad, es decir, los rendimientos por unidad de mano de obra, son muy superiores. Un agricultor del Sahel puede cultivar con la ayuda de un arado una hectárea y obtener de 5 a 6 quintales; mientras que un cerealero oeste-europeo o norteamericano puede fácilmente cultivar solo más de 200 hectáreas y obtener rendimientos de 80 a 100 quintales, 80 x $200=16000$ quintales contra 5. La diferencia de productividad es de 1 a 3.200. Los resultados son tan contrastantes que cabe preguntarse si la competición en el mercado mundial es verdaderamente razonable. A escala planetaria trabajan mil millones 350 mil agricultores, 30 millones en los países ricos se benefician de la mecanización pesada de la segunda revolución agrícola, 300 millones con una agricultura de tracción, mil millones con una agricultura manual.

\section{El papel fundamental de las ayudas de firmas privadas y los Estados}

\section{a. Las firmas privadas}

Las industrias agroalimentarias representan el 2\% del PIB mundial contra el 3\% para la agricultura sola, según los cálculos de la FAO. Es en el marco de 'sistemas agroalimentarios' y no solo agrícolas que conviene abordar la cuestión. Las empresas se caracterizan por una concentración industrial muy fuerte: para la fabricación de material agrícola (J.Deere, Massey Fertguson, Class...), para las semillas y productos fitosanitarios: Dupont Pionner (Estados Unidos), Monsanto (Estados Unidos), cuyo dinamismo y hegemonía han sido compa- 
rados con los de Microsoft, y que son número uno en el creciente poderío del cultivo de plantas OGM; Syngenta (Suiza), Limagrain (Francia), Dow (Estados Unidos) Bayer (Alemania). Por su parte la gran distribución y sus centrales de compra juegan un papel determinante. Los supermercados en el año 2000 detentaban de 50 al $60 \%$ de las ventas en detalle del sector alimentario en los países de América Latina; de 70 a 80\% en Estados Unidos o en Francia. Las firmas transnacionales (Cargill, Louis Dreyfus, Bunge) realizan la mayor parte del mercado de granos.

\section{b. Los Estados promocionan a los agricultores de diferentes maneras}

Préstamos bonificados para la compra de insumos, provisión de agua gratuita para riego, precios mínimos garantizados o ayudas directas. Las estructuras de intervención, de fijación de precios han tenido una real eficacia, pero han sido ampliamente desmantelados en el contexto de políticas neoliberales y de ajuste estructural en los países del Sur.

\section{¿Los agrocarburantes responsables de la subida de los precios?}

Los agrocarburantes se han desarrollado de acuerdo a la demanda de los Estados. Durante la primera crisis petrolera en 1975, Brasil lanzó el plan Poralcohol tendiente a desarrollar un parque automotriz que funciona al alcohol de caña de azúcar o al menos en mezcla. En los años noventa la utilización de los agrocarburantes se generalizó por la superproducción agrícola estructural de los países desarrollados y por el carácter limitado de los recursos fósiles. Los productos llamados 'biocarburantes' son percibidos positivamente, ya que dan empleo y ganancias a los agricultores y constituyen un paso hacia la independencia energética (siendo rentables cuando el barril de petróleo supera los 80 dólares).

Existen dos tipos de agrocarburantes. De un lado, los sustitutivos de la gasolina, el etanol, fabricado o bien a partir de plantas azucareras como la remolacha y sobre todo la caña de azúcar, o bien a partir de cereales, maíz americano o trigo y cebada europeos. De otro lado, hay substutivos del diesel, el 'biodiesel', fabricado a partir de oleoginosas como la palma o la colza o leguminosas como la soya. Pero a partir de 2008 el discurso cambia: tras haber sido presentada 
como la panacea, los agrocarburantes concentran desde entonces demasiadas resistencias. Su efecto medioambiental sería desastroso debido a lo que provocan sus ingredientes al ser producidos: deforestación, destrucción de bosques primarios, todo ligado a la extensión de las plantaciones como la de palma de aceite en Malasia o Brasil. Los pequeños campesinos quedan excluidos del cultivo de grandes propiedades. Son esencialmente las sociedades privadas del agrobusiness, nacionales o extranjeras, que obtienen el provecho de estas opciones. Los precios de las producciones agrícolas aumentan, cuando son ellas la base de la alimentación de los más pobres.

Para el trigo y el maíz, la parte de la producción consagrada a los agrocarburantes es irrelevante. A la inversa del maíz, los Estados Unidos dedican el tercio de su cosecha a la producción de etanol, gracias a las subvenciones de la ALENA (Asociación de libre cambio norteamericana, en inglés NAFTA), lo que ha afectado profundamente las poblaciones urbanas mexicanas habituadas a procurarse maíz importado barato para alimentarse (la famosa tortilla o galleta de maíz).

Frente a la amplitud de los desafíos alimentarios parece absurdo consagrar superficies agrícolas de calidad a las producciones energéticas de dudosa rentabilidad. Los agrocarburantes pueden permitir valorizar tierras marginales, volver a cultivar provisionalmente barbechos ligados a la sobreproducción en Europa o Estados Unidos. El futuro queda abierto gracias a los posibles progresos de pistas de segunda generación basadas en la biomasa no alimentaria (paja, ramas, hojas) y de tercera generación utilizando algas.

\section{La cuestión de la durabilidad de las agriculturas y respeto del medio ambiente}

Si el planeta ha podido nutrir 3 mil millones de personas más entre 1960 y 2000 es, en más de un $90 \%$, en razón de la fuerte progresión de los rendimientos por hectárea de la agricultura 'productivista' de los países ricos y de la 'revolución verde' de los países en vías de desarrollo. Mientras que la población mundial está llamada a aumentar de nuevo 3 mil millones entre 2000 y 2050, estas agriculturas productivistas chocan con limitaciones técnicas en razón de las recaídas negativas sobre el medioambiente, ya se trate de aguas, suelos o 
paisajes. De ahí la preocupación de pasar a formas de agriculturas sustentables, es decir más respetuosas del medioambiente. Estas pueden presentarse de formas diferentes.

La agricultura biológica se posiciona en oposición casi total a la agricultura productivista, rehusando todo uso de productos químicos sintéticos. La agricultura biológica oficialmente certificada representa, en 2007, 31 millones de hectáreas en el mundo, menos del 1\% de las tierras agrícolas. En la Unión Europea supone el 4\% de las superficies cultivadas: en Francia 2\%, Alemania $5 \%$, Suiza $11 \%$, Austria 14\%, Liechtenstein $28 \%$. El objetivo fijado por "Grenelle del ambiente" en Francia de 6\% de tierras agrícolas consagradas al "Bio" en 2012 parece difícil de alcanzar. El problema aquí es productivo: presenta un promedio de rendimientos de 30 a $40 \%$ inferiores a los de la agricultura convencional, según un estudio reciente del INRA (Instituto nacional de la investigación científica).

En los países ricos el hándicap de los rendimientos inferiores es compensado por precios más elevados de 25 a $30 \%$. Por ello, solo los consumidores más acomodados pueden consumir productos bio de manera regular y sostenida. La agricultura biológica no podrá alimentar al planeta, lo que sin embargo cuestionan los ecologistas. Entre miles de millones de personas que sobreviven hoy en situación de subalimentación crónica casi tres cuartos pertenecen a familias de agricultores que practican en su mayoría agriculturas biológicas no certificadas, por falta de acceso a insumos de origen industrial. "A escala planetaria hay más agricultores para salir del bio que para entrar" (JP. Charvet).

La agricultura razonada se presenta como una forma de agricultura sustentable, pero presenta una ruptura menos marcada con la agricultura productivista. En Francia es defendida por las organizaciones agrícolas, y validada o certificada por los poderes públicos. Entre sus objetivos figura la reducción del recurso a los productos fitosanitarios. Se trata de emplearlos de manera comedida, razonada, gracias a análisis más precisos y numerosos de los suelos y de las plagas, una reducción de 20 a $30 \%$ de pesticidas, pero no más. Se señalan también el control de los riesgos sanitarios, la consideración del bienestar de los animales, la gestión de la biodiversidad y de los paisajes, una gestión más fina y económica del riego. La agricultura razonada requiere competencias técnicas de alto nivel. Es la más recomendada y la que se desarrolla más rápidamente. 
Después de la reforma de la PAC (Política agrícola común de la Unión Europea) de junio 2003 se ha establecido una 'eco-condicionalidad' de las ayudas directas a los agricultores. La transferencia integral de las ayudas implica obligaciones de rastreo de los productos, la instalación de una cobertura vegetal en invierno (que se hace abono verde en las tareas de la primavera), la implementación de buenas prácticas agronómicas y medioambientales. Al mismo tiempo, la segunda columna de la PAC, la columna rural ha sido reforzada pasando de menos del $10 \%$ a casi un cuarto del presupuesto del PAC: es la preocupación del desarrollo rural en su globalidad, en particular en las regiones donde las condiciones agronómicas son ingratas — como las regiones de montaña- para sostener las agriculturas 'campesinas' y mantener los campos vivos. Para el periodo 2010-2013 se ha previsto que a esta segunda columna se le atribuya el cuarto del presupuesto total de la PAC.

Una tercera vía exploran agrónomos (Michel Griffon o Marc Dufumier) y agricultores: la agricultura ecológicamente intensiva. Un concepto aparecido a finales de los años noventa pretende aumentar los rendimientos presentando resultados medioambientales satisfactorios tanto en el Norte como en el Sur. Se trata de una vía en curso de exploración pero ciertamente interesante. Se propone orientarse hacia sistemas agrícolas diversificados en el espacio y el tiempo, sin mayores costos de energía fósil ni el recurso intensivo a insumos y productos fitosanitarios, asociando simultánea o sucesivamente en un mismo terreno muchas especies y variedades. Estas asociaciones de cultivos recubren los suelos, los protegen de la erosión, limitan el avance de agentes patógenos. La investigación agronómica debe interesarse en las prácticas tradicionales para hacerlas evolucionar y mejorar con la ayuda de la ciencia y las biotecnologías, para mejorar la resistencia de las plantas y su productividad. Esta 'intensificación ecológica' no es en ningún caso un retorno a los antiguos modelos de agricultura. 


\section{Las cuestiones en suspenso}

\section{¿Faltarán las tierras agrícolas?}

a. Hay numerosas tierras disponibles. Los países ricos han optado por limitar voluntariamente su producción para reducir la oferta y hacer así subir los precios de los productos agrícolas, que se desploman a causa de la sobreproducción. Por ejemplo, si Europa decidiera poner en cultivo sus tierras actualmente en barbecho dispondría de 20 millones de toneladas de cereales más, es decir más que las importaciones alimentarias del África subsahariana. De 13,3 mil millones de hectáreas de superficies emergidas de la tierra solo 1,5 mil millones están cultivadas, de las cuales 600 millones con cereales y otros 2 podrían ser cultivables. África como América Latina cuentan todavía con numerosas tierras disponibles. Según la FAO solo el $20 \%$ de tierras cultivables son utilizadas en ambos continentes. No es lo mismo en Asia y en África del Norte. En Asia, la mayor parte de los espacios productivos están ocupados y han alcanzado altos rendimientos gracias a siglos de mejoramientos técnicos. El Magreb y Medio Oriente tienen un espacio agrícola raro por la aridez general del medio natural.

b. Hay Estados que adquieren tierras en el extranjero para garantizar su seguridad alimentaria. Tal estrategia no es nueva: muchas ciudades antiguas lo practicaron (Roma, Atenas), así como ciertos gobiernos europeos colonizadores. Hoy los países inversionistas son países desarrollados o en vías de desarrollo generalmente ricos, pero dependientes desde el punto de vista alimentario. Entre ellos los Estados petroleros del Golfo pérsico, Japón, Corea del Sur, China e India (dependientes de productos oleoginosos). China dispondría de 1024 millones de hectáreas de tierras agrícolas en Filipinas, 70 mil hectáreas en Maos, 80400 en Rusia, 10 mil en Camerún. Arabia Saudita ha adquirido 900 mil hectáreas de tierras agrícolas en Pakistán y 378 mil en Sudán.

Estos países de acogida son numerosos en África subsahariana (RDC, Madagascar, Mali), pero también en Asia (Indonesia, Cambodia), en América Latina (Brasil), en Europa oriental (Rusia, Ukrania, Rumania). Estas inversiones se hacen con fondos soberanos directamente vinculados a los Estados o con fondos de inversión y de firmas privadas, que anticipan los beneficios que podría provenir de un alza a mediano plazo de los precios de los principales pro- 
ductos agrícolas así como de las plusvalías sobre la propiedad agrícola en caso de reventa de tierras. El conjunto de este fenómeno es difícil de evaluar, ya que muchos acuerdos son confidenciales o informales. Según el informador de Naciones Unidas sobre el derecho a la alimentación, el movimiento parece haber concernido a entre 15 y 20 millones de has. (cifra comparable a la superficie cultivada de Francia) entre 2006 y 2009.

¿Cuál es el impacto de estos enclaves agrícolas extranjeros? Dos son los riesgos: el primero es el desalojo de los agricultores locales que se verían privados de sus tierras, sobre todo allí donde los derechos de uso no están bien establecidos, donde los catastros faltan, como en África. El segundo concierne el medioambiente: la implantación de granjas gigantes poco vinculadas al medio local y muy especulativas no concuerda en general con una gestión "sostenible" del medioambiente.

\section{¿Qué tipo de estructura agrícola favorecer? ¿Grandes empresas o explotaciones familiares?}

En el mundo actual la inmensa mayoría de estas estructuras son explotaciones familiares, que concentran un buena parte de las insuficiencias alimentarias y de la pobreza. Se discute, pero la mayoría de los especialistas observan que la explotación individual ha dado los mejores resultados bajo todos los climas y en todas las civilizaciones. En todo caso, lo más frecuente y el mejoramiento de la seguridad alimentaria mundial pasa por el aumento de la productividad de estas explotaciones. Aunque será necesario resolver los problemas de la propiedad y del acceso al uso. Esto implica reformas agrarias en los países con mayores desigualdades. Las reformas agrarias tienen dos objetivos: uno social, por la redistribución de las tierras y otro productivo, que requiere la instalación de estructuras de organización de los productores en beneficio de una clase media de explotadores agrícolas. Las reformas agrarias deben completarse con la disponibilidad de crédito, de insumos, insfraestructuras necesarias para producir y vender. La amplitud de las reformas agrarias ha sido muy diversa según los países. Desde finales de los años ochenta las reformas agrarias se han paralizado. Y en países que han tenido reformas agrarias de tipo colectivista (Cuba, Argelia, China, Vietnam) se ha ido sucediendo una descolectivización, que ha 
provocado la aparición de una categoría de pequeños y medianos productores dinámicos y que explica el crecimiento de las producciones y el receso de la subalimentación en países como China o Vietnam.

En África subsahariana el estatuto de la tierra es incierto y plantea problemas, sobre todo la yuxtaposición de tres derechos: el derecho tradicional según el cual la tierra pertenece a la comunidad, el derecho individual europeo y, finalmente, la nacionalización por el Estado de todo o una parte del suelo. Esta situación crea un clima de incertidumbre en la propiedad del suelo poco favorable al desarrollo agrícola, ya que no incentiva la inversión.

\section{Una intensificación necesaria pero suficiente: el ejemplo de la India}

India ofrece las ventajas y los límites de las soluciones técnicas. Es el país que ha efectuado los progresos agrícolas más notables y que cuenta con más de un cuarto de los malnutridos del planeta. Todo se acelera en los años 1964-65 considerados nefastos para la India: muerte de Nehru, derrota ante la China, malas cosechas, guerra con Pakistán. En Bihar 100 mil personas mueren de hambre. La India está obligada a importar 10 millones de toneladas de arroz y trigo, pero el presidente de EE.UU. Johnson, retrasa la partida de los navíos cerealeros para obligar a la India a revisar sus posiciones antinorteamericanas en la guerra de Vietnam. El gobierno indú decide que semejante humillación no se producirá jamás y que el país debe dotarse de la autosuficiencia alimentaria. Se lanza entonces un programa en germen desde hace 6 años, la 'revolución verde'. Se trata de una doble mutación, a la vez técnica y económica. Nuevas variedades de cereales de alto rendimiento (VHR), trigo primero y arroz después, son propuestas al campesinado; las que producen dos veces más que las variedades tradicionales a condición de emplear insumos pesticidas y riego. Estas variedades híbridas han sido perfeccionadas en grandes centros de investigación agronómica de México (CIMMYT) y Filipinas (IRII) con la ayuda pública y privada norteamericana. El director del centro de investigación mexicano, Norman Borlaug, obtiene el premio Nobel de la Paz en 1970.

El Estado indú interviene: subvenciona la compra de semillas e insumos y se compromete a comprar las cosechas a precios estimulantes, subvencionando su venta a bajo precio a consumidores modestos, en particular urbanos. Muy 
criticada en sus inicios porque aumentaba las desigualdades entre campesinos medios o acomodados y campesinos pobres y sin tierra que no tenían los medios para comprar los CHR; sin embargo, la revolución verde ha permitido a la India responder al desafío demográfico. En 40 años la producción de arroz y de trigo se ha multiplicado por 2,5: 80 millones de toneladas en 1960, 200 millones en 2001, mientras que la población duplica 510 millones en 1960 y 1,03 mil millones en 2001. En el intervalo las disponibilidades alimentarias han aumentado el 20\% por habitante; en 1975 la India alcanza la autosuficiencia alimentaria. En 1977 entra en el club de los países exportadores de cereales.

Son las tierras más fértiles y mejor regadas de la llanura del Indo-gangético y los deltas que se han beneficiado de esta revolución. De 1950 a 1980 las superficies regadas se duplican y más de 1500 represas son construidas. Se generalizan los pozos entubados a gran profundidad que extraen el agua gracias a bombas eléctricas. La revolución verde es pues un éxito agrícola que ha permitido una ampliación del mercado del empleo agrícola y no agrícola en las regiones concernidas, la electrificación de las aldeas, el desarrollo de industrias químicas y agroalimentarias. Importadas al inicio del proceso, las semillas, insumos y pesticidas son hoy mayoritariamente fabricadas por la industria nacional. Las empresas de semillas indias, públicas y privadas, hoy son muy poderosas al igual que los productores de insumos, gracias a los cuales la India se sitúa en el tercer lugar mundial, después de China y Estados Unidos. Desde hace 15 años en las regiones más secas se difunden las oleoginosas: la 'revolución amarilla' fundada en el maní, la colza, el girasol, la ricina y el cotón.

\section{Este éxito debe ser relativizado}

Hay un fracaso social. La malnutrición crónica ligada a la pobreza y las desigualdades sociales subsisten; mientras que el país conoce un crecimiento económico fuerte, y no hay guerra civil ni crisis política como en muchos otros países. A inicios de los noventa la situación alimentaria y agrícola se deteriora, a consecuencia de la liberación comenzada en 1991, que conduce al gobierno a disminuir las subvenciones a los precios de insumos destinados a los más pobres, pero también a causa de la burocratización y corrupción que minan la administración del país. Los stocks se amontonan en las tiendas del Estado. En 
el verano de 2010 la prensa evoca 60 millones de toneladas acumuladas, que se pudren en los hangares o bajo lonas de plástico (diario La Croix 1, septiembre de 2010). Los más pobres, que pueden comprar hasta $356 \mathrm{~kg}$ de cereales subvencionados por mes, en realidad no se benefician, ya sea porque no existen tiendas del Estado en las regiones rurales aisladas, o porque las familias no disponen de la tarjeta de alimentación en los suburbios, o porque los responsables de las tiendas revenden la mercancía subvencionada o exigen coimas que excluyen a los más pobres. Así un quinto de la población indú no tiene acceso a una alimentación suficiente o porque reside en regiones áridas o semiáridas no regadas (más de un tercio del territorio indú), que no han sido beneficiadas por los progresos agrícolas, o porque forma parte de los excluidos del progreso: las castas inferiores o los marginales a las castas, los asalariados agrícolas en situación precaria, que representan la mitad de los activos agrícolas en un país donde la distribución de las tierras sigue siendo muy desigual.

Los límites son también agronómicos. Los rendimientos alcanzan un techo desde hace algunos años. A la vez consecuencia de menores subvenciones acordadas a la utilización de insumos pero también a la consecuencia ecológica de la revolución verde. Numerosas tierras están saturadas de productos químicos y el granero de trigo, que es el Pendjab, sufre la emergencia de la sal. Las capas freáticas han descendido considerablemente y presentan problemas crecientes de salinización y de polución de nitratos y pesticidas. La irrigación, con frecuencia excesiva y mal conducida, representa las $4 / 5$ partes de la disponibilidad de agua del país. La casi gratuidad del agua para los campesinos incita al derroche y el sobreconsumo. Se requieren 200 toneladas de agua para producir una tonelada de caña. La mitad del agua se pierde en su transporte. Al derroche del agua se añade el de la electricidad, también subvencionada.

Las respuestas al desafío son agronómicas y políticas. Los agrónomos indús trabajan en dos direcciones complementarias. De una parte prosiguen los esfuerzos a favor de la intensificación de cultivos, perfeccionando nuevas variedades de arroz todavía más productivas. Es la 'super-revolución verde'. De otro lado trabajan en la seguridad alimentaria de tierras más desfavorecidas en el plano climático y de los suelos, elaborando variedades más productivas que las plantas utilizadas tradicionalmente, pero que pueden resistir a las difíciles condiciones respetando los ecosistemas. Es la revolución doblemente verde 
cuyo objetivo es luchar contra la pobreza rural respetando el medioambiente. En ambos casos la investigación apunta a la ingeniería genética. Por ejemplo el "arroz dorado" incluye micronutrientes como el hierro. Pero es solo en el dominio del cotón, que moviliza la mitad del consumo de pesticidas, que los OGM se han impuesto en la India. La firma Monsanto ha obtenido en el año 2000 la autorización de comercializar el cotón Bt genéticamente modificado para resistir a los depredadores, y ocupa tres cuartos de las superficies de cotón.

El gobierno indú es consciente de los límites del cambio liberal impulsado en India a partir de 1991. El crecimiento económico es ciertamente elevado, pero los pobres no se benefician de él suficientemente. Las privatizaciones han hecho perder muchos empleos, el hambre persiste, el crecimiento demográfico tarda en frenarse. Se trata hoy de rectificar los objetivos con un 'New Deal' para los pobres, invirtiendo de nuevo en la agricultura con la expresa preocupación de la 'equidad' y de la 'justicia social'. Se constata aquí que el problema del hambre no es un problema de producción sino de distribución.

\section{Las biotecnologías contra el hambre}

Hay principalmente dos tipos de plantas genéticamente modificadas:

- A las que ha sido integrada una acción insecticida, siendo el interés un menor consumo de productos fitosanitarios, una ventaja financiera y medioambiental. (Maíz BT nombre de una proteína insecticida extraída del Bacillus Thuriensis)

- A las que un gene confiere la resistencia a un herbicida. Semilla HT (Herbicida Tolerant). Es el tipo de OGM más utilizado, dispensa el deshierbe y simplifica el trabajo del agricultor. 